gastric mucosa is an important predisposing factor. But in Jones and his colleagues' cases the emphasis was on duodenal ulceration, and a purely ischaemic aetiology seems unlikely. A common factor may enter into the causation of both lesions. The severity of atheroma is related to cigarette smoking, ${ }^{6}$ and the evidence points to a relationship between peptic ulceration and smoking. ${ }^{7}$ Unfortunately there are no data on the smoking habits of Jones and his colleagues' patients. Be this as it may, it is important to know of the association lest haematemesis in a patient with an abdominal aneurysm is automatically attributed to its incipient rupture.

1 Hudson, R. E. B., Cardiovascular Pathology, Vol. 1, p. 466. London, Arnold, 1965.

2 Antzis, E., Dunn, J., and Schilero, A. J., American fournal of Medicine, $1951,11,531$

3 Jones, A. W., Kirk, R. S., and Bloor, K., Gut, 1970, 11, 679.

Elkeles, A., American Fournal of Roentgenology, Radium Therapy and Nuclear Medicine, 1964, 91, 744

5 Jones, F. A., Gummer, J. W. P., and Lennard-Jones, J. E., Clinical Gastroenterology, 2nd edn., p. 471. Oxford, Blackwell Scientific, 1968. - British Medical fournal, 1969, 1, 460.

7 United States Public Health Service, Smoking and Health: Report of the Advisory Committee to the Surgeon General. Washington, Government Advisory Committee to
Printing Office, 1964.

\section{People's Preferences}

The contrast between private affluence and public squalor has grown more striking in Britain, according to a report published last week, as families enjoying higher standards of food, domestic equipment, and holidays are confronted with continuing deficiencies in medical care, schools, housing, and, for an important minority, pensions. ${ }^{1}$ Published by the Institute of Economic Affairs, the report is based on a survey of opinion carried out to discover people's preferences in paying for the welfare services.

For some time politicians of all parties have been agreeing that direct taxation has reached the limit the population will stand. Yet there is a good deal of evidence-for example, from schemes of private saving and insurance-that many people do not wish to rely on State welfare alone. They want better services but object to the Treasury extracting the money to pay for them. That people holding these ideas form a substantial proportion of the general population seems clear from the present report. As many as $73 \%$ of the sample questioned, for instance, thought that "people should be allowed to pay extra for their health and education and pension arrangements." At the same time $85 \%$ agreed that "everybody, rich or poor, is entitled to equal treatment in the social services." And $24 \%$ thought that "people should not be allowed to pay extra for the heaith services they need outside the (National) Health Service." On the question of paying for the Health Service $66 \%$ of the sample thought the present system should be left unchanged. But that as many as a third should favour a change to other methods deserves attention. As the report puts it, if one in three brought up on all-party blessing for the N.H.S. is prepared to take a chance on an unknown method of obtaining medical care, the N.H.S. cannot be giving the high standards claimed for it by sociologists, politicians, and others.

Since the inquiry was based on interviews for an average of 45 minutes with 2,005 men and an admittedly not fully representative sample of 199 women its conclusions must be treated with reserve. But they do suggest that though there are expected differences on the average between people in the upper and lower socioeconomic classes there are also unexpected concordances. Not for the first time the politicians of both the main parties may know less about their constituents' opinions and wishes than they think they do. In other words, they may have greater freedom to set about improving the welfare services than they had dared to hope. That "equal treatment" should be available to all who use the Health Service is obviously the wish of the overwhelming majority of people in the country, whether patients or workers in the service, and to that should be added the condition that full medical care is obtainable by all who need it irrespective of their means. But neither of these aims is necessarily incompatible with fresh approaches to financing health services.

Harris, R., and Seldon, A., Choice in Welfare 1970. London, Institute of Economic Affairs, 1971.

\section{Geriatric Day Hospitals}

In 1960 there were only a dozen geriatric day hospitals in Britain. By the end of last year there were 119 and several more were being built. Day hospitals started in other countries -Russia, Canada, and the U.S.A. all having introduced them for psychiatric patients in the early 1940s-but their use in geriatrics has been largely developed in Britain, where most consultants now believe that they are an essential part of the geriatric service. A point when expansion is slowing down is always a good time for taking stock, and a recent review of day-hospital principles and practice ${ }^{1}$ should do much to persuade the unconvinced $4 \%$ of geriatric consultants in this country that further development is worthwhile. It should also encourage further expansion abroad.

Most of the patients who attend day hospitals do so for rehabilitation or the maintenance of physical independence. They come in roughly equal proportions from hospital doctors and general practitioners. Day hospitals are usually closely linked with ordinary hospitals (either general or geriatric) -an arrangement which enables them to share physiotherapy, occupational therapy, diagnostic, and treatment services. The typical day hospital in Britain provides over 20 places and has a staff of nurses, physiotherapists, and occupational therapists. Patients are usually brought in by ambulance and attend once or twice a week-in two-thirds of cases for less than a year. Their progress is reviewed at regular case conferences or review clinics. Once experience has been gained in running the day hospital, there is a definite change in the pattern of care: the proportion of patients discharged by the staff increases and that of patients discharging themselves decreases, indicating that the selection of patients is better.

This report shows clearly that the day hospital has an essential role in any full geriatric service. It acts as a midway house between the hospital inpatient geriatric unit and the community social day centre. But not only does the existence of a day hospital enable inpatients to be discharged earlier: it stimulates the morale of all concerned, and it encourages further development of the local facilities for old people. As Professor J. C. Brocklehurst points out in his conclusion, it "acts as a window through which the staff of the whole geriatric department can see the fruits of their labours as their elderly patients are resettled and maintained in the community."

1 Brocklehurst, J. C., The Geriatric Day Hospital. London, King Edward's Fund for London, 1970. 